\title{
Time course of concurrent infection with dengue virus serotypes 2 and 4 detected in urine
}

\author{
Methee Sriprapun a,b,c, Chalinee Laosakul ${ }^{\mathrm{b}, \mathrm{c}}$, Sunisa Krajiw ${ }^{\mathrm{b}, \mathrm{c}}$, Kesinee Arunyingmongkol ${ }^{\mathrm{b}, \mathrm{c}}$, Padet Siriyasatien ${ }^{\mathrm{b}, \mathrm{d}}$, \\ Wanla Kulwichitt,c \\ Interdisciplinary Program of Biomedical Sciences, Faculty of Graduate School, Chulalongkorn \\ University, Bangkok 10330, Thailand \\ ${ }^{b}$ King Chulalongkorn Memorial Hospital Clinical Excellence Center for Infectious Diseases of National \\ Concern, Bangkok 10330, Thailand \\ 'Department of Medicine, Faculty of Medicine, Chulalongkorn University, Bangkok 10330, Thailand \\ ${ }^{d}$ Department of Parasitology, Faculty of Medicine, Chulalongkorn University, Bangkok 10330, Thailand
}

\begin{abstract}
Background: In hyperendemic areas, concurrent multiserotype dengue virus (DENV) infections commonly occur in both humans and in mosquito vectors. Previous studies have focused on single blood specimens.

Objectives: To illustrate and characterize the time course of mixed infection with DENV serotypes 2 (DENV2) and 4 (DENV4) in a single case.

Materials and methods: Plasma, saliva, and urine were collected from a patient diagnosed with dengue hemorrhagic fever grade II and secondary DENV infection on days 7, 18, and 31 of his illness. DENV RNA detection was performed using 2 DENV-specific reverse transcriptase-polymerase chain reaction protocols. Cloning and sequencing were performed to quantify the major and minor viral populations in dual-serotype-infected specimen(s). Genotypes of both DENV serotypes were characterized.

Results: DENV genome was detected in plasma and saliva only at the first time point (day 7 of illness), but in urine at both the first and second time points (days 7 and 18 of illness). DENV4 serotype was found in all DENV genome-positive specimens. DENV2 serotype was unexpectedly also detected in the first urine specimen. DENV4 as the major and DENV2 as the minor population. The DENV2 serotype was clustered in genotype Asian I and DENV4 serotype in genotype I.

Conclusion: To our knowledge, this is the first report of concurrent multiserotype DENV infection detected solely in urine. Prospective noninvasive investigations may determine the prevalence of this phenomenon. Clinical and public health implications of this finding need to be explored.
\end{abstract}

Keywords: Concurrent, dengue virus, mixed infection, multi-serotype, saliva, urine

Dengue virus (DENV) infection is a major health problem in tropical and subtropical countries. The virus consists of 4 serotypes: DENV1-DENV4. DENV are positive single-stranded RNA viruses in the family Flaviviridae, which contains 3 structural (capsid (C), membranes (M), and envelope (E)) and 7 nonstructural genes (NS1, NS2A, NS2B, NS3, NS4A, NS4B, and NS5) for a total length of approximately $11 \mathrm{~kb}$. Transmission of this virus occurs via the vectors Aedes aegypti and Aedes albopictus [1]. A wide range of clinical symptoms is found in infected patients ranging from asymptomatic infection,

Correspondence to: Assoc. Prof. Wanla Kulwichit, MD, Department of Medicine, Faculty of Medicine, Chulalongkorn University, Bangkok 10330, Thailand. E-mail: wanla@chula.md dengue fever and, dengue hemorrhagic fever (DHF) to dengue shock syndrome [2].

Previous studies by our group and by others have shown that, during acute infection, DENV genome is detectable in blood, saliva, and urine samples [3-6]. In addition, concurrent infections with multiple serotypes can occur in both infected mosquitoes and humans [7-10]. Here, we present a case of dual DENV infections with DENV2 and DENV4 serotypes in the urine at a single time point. The 'minor' serotype disappeared in subsequent specimens.

\section{Materials and methods \\ Patient and specimen collection}

This study was approved by the Institutional Review Board, Faculty of Medicine, Chulalongkorn University (COA No. 478/2008 and 877/2009). 
Plasma, saliva, and urine were collected from a 28-year-old man hospitalized at King Chulalongkorn Memorial Hospital, Bangkok in late July 2008 after written informed consent was provided by this patient on an approved form. The patient had been febrile for 6 days. Specimens were collected on days 7,18 , and 31 of his illness. He was diagnosed as having DHF grade II according to the World Health Organization criteria [11]. An anti-DENV-specific enzyme-linked immunosorbent assay (ELISA) revealed an IgM:IgG ratio of less than 1.8 (Table 1), suggesting a secondary DENV infection [12]. Stock DENV1 (Hawaii), DENV2 (16681), DENV3 (H87), and DENV4 (814669) were used as positive controls for molecular assays.

\section{Viral RNA extraction and nested reverse transcription-polymerase chain reaction (nested RT-PCR)}

Viral RNA was extracted from all collected specimens in a volume of $140 \mu \mathrm{L}$ each, using QIAamp Viral RNA Mini Kits (Qiagen, Hilden, Germany) following the manufacturer's instructions. Extracted viral RNA (5 $\mu \mathrm{L}$ aliquot of the $140 \mu \mathrm{L}$ sample) was subjected to nested RT-PCR using the primers described by Yenchitsomanus et al. [13]. First round RT-PCR was performed using a Qiagen OneStep RTPCR Kit with a left and right pair of DENV genome envelope (E) region outer universal primers (DEUL and DEUR) in a total reaction mixture of $50 \mu \mathrm{L}$. Reverse transcription was performed at $50^{\circ} \mathrm{C}$ for $40 \mathrm{~min}$. Activation of HotStarTaq DNA Polymerase (Qiagen) was set at $95^{\circ} \mathrm{C}$ for $15 \mathrm{~min}$, followed by 40 cycles of denaturation at $94^{\circ} \mathrm{C}$ for $1 \mathrm{~min}$, annealing at $42^{\circ} \mathrm{C}$ for $1 \mathrm{~min}$, and extension at $72^{\circ} \mathrm{C}$ for $1 \mathrm{~min}$, followed by a final extension at $72^{\circ} \mathrm{C}$ for $10 \mathrm{~min}$. The first PCR product $(1 \mu \mathrm{L}$ aliquot of the $50 \mu \mathrm{L}$ reaction mixture) was used for the nested reaction with a left and right pair of DENV genome $\mathrm{E}$ region inner or nested universal primers (DENUL and DENUR). The polymerase was activated at $95^{\circ} \mathrm{C}$ for $15 \mathrm{~min}$, followed by 35 cycles of denaturation at $94^{\circ} \mathrm{C}$ for $1 \mathrm{~min}$, annealing at $58^{\circ} \mathrm{C}$ for $1 \mathrm{~min}$, and extension at $72^{\circ} \mathrm{C}$ for $1 \mathrm{~min}$, with a final extension at $72^{\circ} \mathrm{C}$ for $10 \mathrm{~min}$. The PCR product was $434 \mathrm{bp}$ for all 4 serotypes. The PCR experiment and the detection step were conducted in separate laboratories. All standard and strict precautions for PCR were carefully followed for all reactions performed.

\section{Serotype-specific seminested RT-PCR}

Serotype-specific RT-PCR was performed on the specimens determined to be DENV-positive by the nested RT-PCR above. The protocol was described by Lanciotti et al. [14]. The reverse transcription was performed using SuperScript III First-Strand Synthesis System (Invitrogen, Carlsbad, CA, USA) following the manufacturer's instructions. Briefly, a $5 \mu \mathrm{L}$ aliquot of the $140 \mu \mathrm{L}$ sample of viral RNA was incubated with the DV2 primer in a total volume of $10 \mu \mathrm{L}$ at $65^{\circ} \mathrm{C}$ for $5 \mathrm{~min}$, and chilled on ice for $2 \mathrm{~min}$. The cDNA synthesis was performed at in a total volume of $20 \mu \mathrm{L} 50^{\circ} \mathrm{C}$ for $50 \mathrm{~min}$, and then $85^{\circ} \mathrm{C}$ for 5 minutes. Subsequently, RNase $\mathrm{H}(1 \mu \mathrm{L})$ was added and incubated at $37^{\circ} \mathrm{C}$ for 20 min. A first-round PCR was performed using a $2.5 \mu \mathrm{L}$ aliquot of each cDNA reaction mixture with DENV serotype-specific primers DV1 and DV2 and HotStarTaq DNA Polymerase in a total reaction mixture of $50 \mu \mathrm{L}$ ). The polymerase was activated at $95^{\circ} \mathrm{C}$ for $15 \mathrm{~min}$, followed by 35 cycles of denaturation at $94^{\circ} \mathrm{C}$ for $1 \mathrm{~min}$, annealing at $55^{\circ} \mathrm{C}$ for $1 \mathrm{~min}$, and extension at $72^{\circ} \mathrm{C}$ for $1 \mathrm{~min}$, with a final extension at $72^{\circ} \mathrm{C}$ for $10 \mathrm{~min}$. The first-round PCR product $(1 \mu \mathrm{L}$ aliquot of the $50 \mu \mathrm{L}$ reaction mixture) was used as the template for the seminested reaction. The primers were D1 and a specific primer for each of the 4 serotypes (DV1 and type-specific (TS)1, DV1-TS2, DV1-TS3, and DV1-TS4). Twenty-five cycles of the same PCR conditions as used for the first round were performed. The PCR products were $482 \mathrm{bp}$ for DENV1, 119 bp for DENV2, 290 bp for DENV3, and 392 bp for DENV4.

\section{Cloning and sequencing}

Each 434 bp of nested RT-PCR product was ligated into a pCR8/GW/TOPO TA Cloning Kit (Invitrogen) and transformed into StrataClone SoloPack Competent Cells (Stratagene, Agilent Technologies, Santa Clara, CA, USA) following the manufacturer's instructions. Ten to 15 colonies from each specimen were sequenced using both universal forward and reverse primers (M13 forward and T7 promoter) by 1st Base (Selangor Darul Ehsan, Malaysia). Each chromatogram was checked using Chromas Lite (version 2.1.1) and corrected manually. The DENV serotype identification in each sequence was investigated using the BLAST algorithm in GenBank (http://www.ncbi.nlm.nih.gov/BLAST). The DENV genotype was analyzed using DENV genotype determination tool in Viral Bioinformatics Research Center [10]. A number of clones representing each serotype in each specimen were investigated. 


\section{Results \\ Patient characteristics}

The 28-year-old man hospitalized with 4 days of high undifferentiated fever $\left(39.2^{\circ} \mathrm{C}\right)$ with chills and headache denied prior clinical DENV infection. The patient was hemoconcentrated (with peak hematocrit of 47.2\%), had leukopenia (with nadir leukocyte count of 2,020 per $\mathrm{mm}^{3}$ ), and thrombocytopenic (with nadir platelet count of 8,000 per $\mathrm{mm}^{3}$ ). Urinalysis revealed $1+$ protein, but otherwise was unremarkable. Aspartate transaminase was elevated at $181 \mathrm{IU} / \mathrm{L}$ and alanine transaminase was elevated at $165 \mathrm{IU} / \mathrm{L}$. The patient was febrile for 2 more days in hospital and then made an uneventful recovery upon supportive management. Clinical diagnosis was DHF with significant fluid leakage.

DENV genome detection in plasma, saliva, and urine

The patient was concurrently infected with DENV2 and DENV4. DENV RNA was detected in all specimen types at the first time point (day 7 of illness), but at the second time point (day 18 of illness) the virus was found in urine only. DENV4 was detected in all DENV-positive specimens, while DENV2 was found in the first urine specimen only. No DENV genome was detected in any specimens collected at the third time point (day 31 of illness) (Table 1 and Figure 1).

Table 1. ELISA and RT-PCR results for each specimen type on different days

\begin{tabular}{|c|c|c|c|c|c|}
\hline \multirow[t]{2}{*}{ Day of illness } & \multicolumn{2}{|c|}{ ELISA results (plasma) } & \multicolumn{3}{|c|}{ RT-PCR results } \\
\hline & IgM (units) ${ }^{a}$ & IgG (units) ${ }^{\mathrm{b}}$ & Plasma & Saliva & Urine \\
\hline 7 & 26 & 93 & DENV4 & DENV4 & DENV4+DENV2 \\
\hline 18 & 49 & 113 & - & - & DENV4 \\
\hline 31 & 55 & 106 & - & - & - \\
\hline
\end{tabular}

aThe cut-off value of IgM was 40 units. ${ }^{\text {b}}$ The cut-off value of IgG was 100 units.

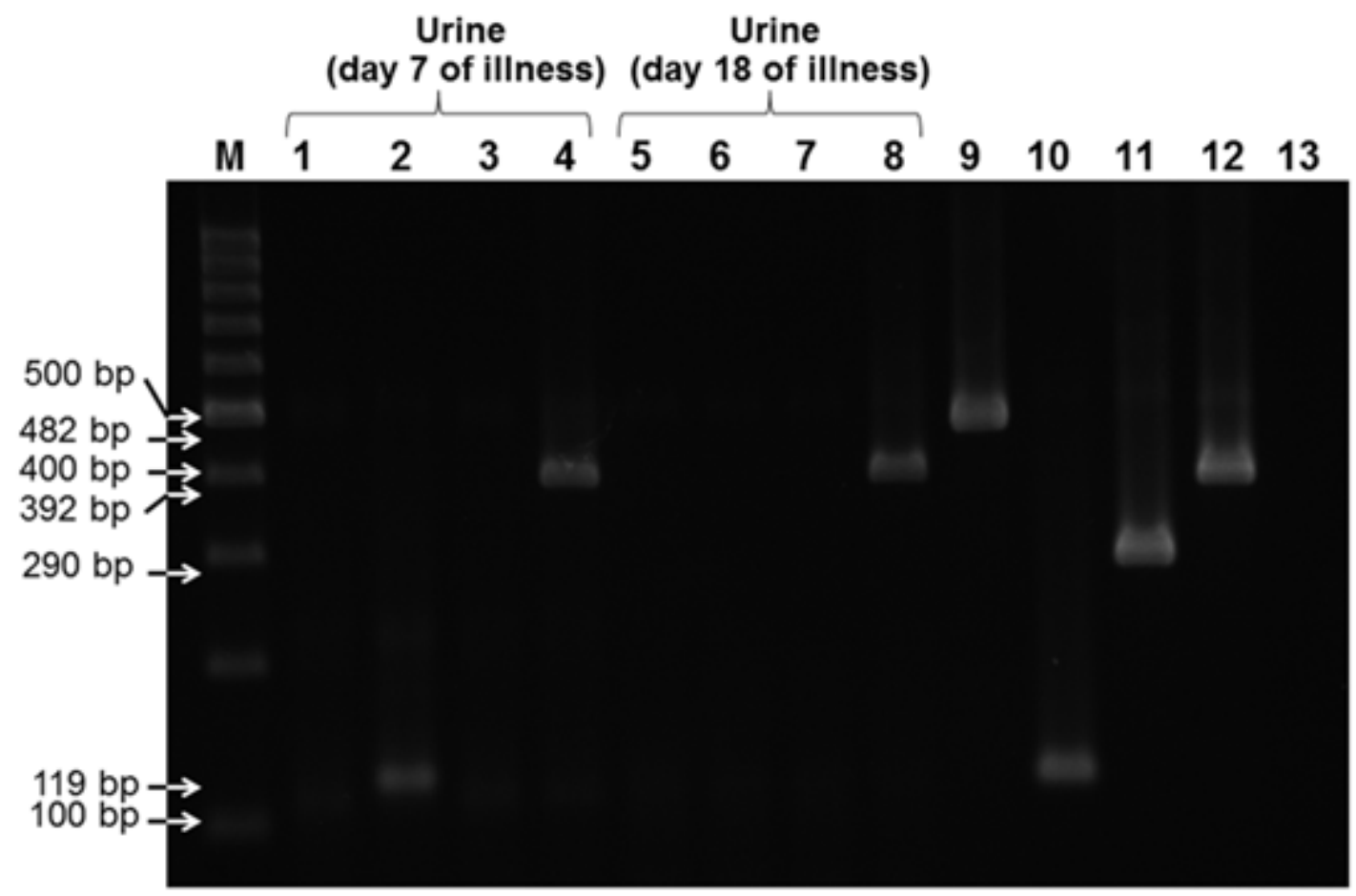

Figure 1. The 2\% agarose gel electrophoresis of serotype-nested RT-PCR products of positive specimens collected at different times. Lanes 1-4 are from urine collected on day 7 of illness. Lanes 5-8 are from urine collected on day 18 of illness (lanes 1 and 5 using dengue virus serotype-specific primer DV1 and type-specific primer (TS1); lanes 2 and 6 using primers DV1 and TS2; lanes 3 and 7 using primers DV1 and TS3; lanes 4 and 8 using primers DV1 and TS4). Lanes 9-12 are positive controls 
Major and minor serotype populations in dualserotype-infected urine

In the 15 analyzed clones from the first urine with biserotype infection by DENV2 and DENV4, 11 clones were of DENV4, and the 4 others of DENV2. Clones from the single-serotype specimens were all of DENV4 (Table 2).

\section{Genotype analysis in each DENV population}

All DENV4 clones were clustered in genotype I, whereas all DENV2 clones were clustered in genotype Asian I (Table 2).

None of the above cloned sequences were similar to DENV sequences and strains used or analyzed in our laboratory in the previous few months.

\section{Discussion}

Concurrent multiserotype infections by DENV have been described in several dengue-prevalent countries [7, 8, 10, 15-17]. The proportion of such patients could be as high as $5 \%-15 \%[16,17]$, and the number of serotypes as many as $3[7,8,15]$. These concurrent infections were confirmed by both serotype-specific RT-PCR [7, 8, 10, 15-17] and viral isolation [7, 16]. Clinical features and severity in monoserotype and multiserotype infections do not appear to be different [8].

DENV has been shown to be excreted in urine and saliva [3-5]. To our knowledge, our group was the first to demonstrate presence of the virus in urine [4], and to show that the urinary virus is still alive and culturable by mosquito inoculation [18]. The kidneys are consistently recognized among target organs for the virus. Findings include inflammatory changes of and presence of DENV-specific antigen or genome in renal tissues of fatal cases [19-23].

The present report notably combines knowledge and challenges to complex dengue pathogenesis.
Clearly, without the DENV molecular assays performed in urine specimens, the patient would have been diagnosed as singly infected with DENV4 alone, based on DENV4 as the only serotype consistently detected in plasma and saliva. While its clinical importance is yet to be elucidated, the phenomenon of concurrent multiserotype DENV infection is probably more common than has been recognized.

\section{Conclusion}

Persistent and mixed DENV serotype infections in plasma, saliva, and urine specimens from different sources at different time points can occur in the hyperendemic regions of DENV infection. Our findings may contribute to a new understanding about the pathogenesis of DENV infection.

\section{Acknowledgments}

The authors thank Kriangsak Limkittikul of the Faculty of Tropical Medicine, Mahidol University, and Robert Gibbons, Butsaya Thaisomboonsuk, and Khunying Ananda Nisalak, Armed Forces Research Institute of Medical Sciences, Bangkok, for providing DENV standard strains. We acknowledge the technical assistance of scientists at the National Institute of Health, Department of Medical Sciences, Thailand, with the ELISAs, and are grateful to the patient for his permission to publish details of his case. This work was supported by Thailand Research Fund, Chulalongkorn University's KFAS Fund, Chulalongkorn University Dutsadi Phiphat Scholarship and Graduate Scholarship to commemorate the 72nd Anniversary of His Majesty King Bhumibol Adulyadej.

The authors have no conflicts of interest to declare.

Table 2. The serotype and genotype analysis of each clone in each specimen type

\begin{tabular}{|c|c|c|c|c|c|c|}
\hline \multirow[t]{2}{*}{ Specimen } & \multirow[t]{2}{*}{ Serotype $^{\mathrm{a}}$} & \multirow{2}{*}{$\begin{array}{c}\text { No. of } \\
\text { selected clones }\end{array}$} & \multicolumn{2}{|c|}{ DENV4 population } & \multicolumn{2}{|c|}{ DENV2 population } \\
\hline & & & No. of clones & Genotype & No. of clones & Genotype \\
\hline Plasma (7) & 4 & 14 & 14 & I & 0 & ND \\
\hline Saliva (7) & 4 & 12 & 12 & I & 0 & ND \\
\hline Urine (7) & $2+4$ & 15 & 11 & I & 4 & Asian I \\
\hline Urine (18) & 4 & 13 & 13 & I & 0 & ND \\
\hline
\end{tabular}

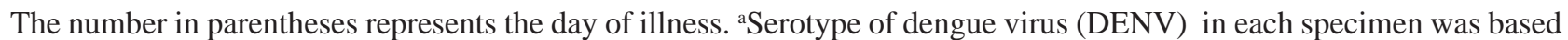
on the serotypic RT-PCR results. ND = not determined. 


\section{References}

1. Guzman MG, Halstead SB, Artsob H, Buchy P, Farrar J, Gubler DJ, et al. Dengue: a continuing global threat. Nat Rev Microbiol. 2010; 8:S7-16.

2. Peeling RW, Artsob H, Pelegrino JL, Buchy P, Cardosa MJ, Devi S, et al. Evaluation of diagnostic tests: dengue. Nat Rev Microbiol. 2010; 8:S30-8.

3. Hirayama T, Mizuno Y, Takeshita N, Kotaki A, Tajima $\mathrm{S}$, Omatsu T, et al. Detection of dengue virus genome in urine by real-time reverse transcriptase PCR: a laboratory diagnostic method useful after disappearance of the genome in serum. J Clin Microbiol. 2012; 50:2047-52.

4. Kulwichit W, Mekmullica J, Krajiw S, Prommalikit O, Yapom R, Intaraprasong P, et al. Highly-sensitive virologic diagnosis of dengue infection by a newlydeveloped protocol of reverse transcription-nested polymerase chain reaction (RT-nested PCR) of serum/plasma, peripheral blood leukocyte (PBL), and urine specimens. The 41st Annual Meeting of The Infectious Diseases Society of America (IDSA); Oct 9-12, 2003. San Diego, California, USA. Arlington: IDSA; 2003. p. 93. [Abstract]

5. Torres JR, Liprandi F, Goncalvez AP. Acute parotitis due to dengue virus. Clin Infect Dis. 2000; 31:E28-9.

6. Mizuno Y, Kotaki A, Harada F, Tajima S, Kurane I, Takasaki T. Confirmation of dengue virus infection by detection of dengue virus type 1 genome in urine and saliva but not in plasma. Trans R Soc Trop Med Hyg. 2007; 101:738-9.

7. Chinnawirotpisan P, Mammen MP, Jr., Nisalak A, Thaisomboonsuk B, Narupiti S, Thirawuth V, et al. Detection of concurrent infection with multiple dengue virus serotypes in Thai children by ELISA and nested RT-PCR assay. Arch Virol. 2008; 153:2225-32.

8. Kulwichit W, Krajiw S, Chansinghakul D, Suwanpimolkul G, Prommalikit O, Suandork P, et al. Concurrent multi-serotypic dengue infections in various body fluids. 19th European Congress of Clinical Microbiology and Infectious Diseases (ECCMID); May 16-19, 2009; Helsinki, Finland. London: Wiley-Blackwell; 2009. p. S19. [Abstract of oral presentation O82]

9. Pessanha JE, Caiaffa WT, Cecilio AB, Iani FC, Araujo SC, Nascimento JC, et al. Cocirculation of two dengue virus serotypes in individual and pooled samples of Aedes aegypti and Aedes albopictus larvae. Rev Soc Bras Med Trop. 2011; 44:103-5.

10. Figueiredo RM, Naveca FG, Oliveira CM, Bastos Mde S, Mourão MP, Viana Sde S, et al. Co-infection of Dengue virus by serotypes 3 and 4 in patients from Amazonas, Brazil. Rev Inst Med Trop Sao Paulo. 2011; 53:321-3.

11. World Health Organization. Dengue: guidelines for diagnosis, treatment, prevention and control. Geneva: WHO Press; 2009.

12. Vaughn DW, Nisalak A, Solomon T, Kalayanarooj S, Nguyen MD, Kneen R, et al. Rapid serologic diagnosis of dengue virus infection using a commercial capture ELISA that distinguishes primary and secondary infections. Am J Trop Med Hyg. 1999; 60:693-8.

13. Yenchitsomanus PT, Sricharoen P, Jaruthasana I, Pattanakitsakul SN, Nitayaphan S, Mongkolsapaya J, et al. Rapid detection and identification of dengue viruses by polymerase chain reaction (PCR). Southeast Asian J Trop Med Public Health. 1996; 27:228-36.

14. Lanciotti RS, Calisher CH, Gubler DJ, Chang GJ, Vorndam AV. Rapid detection and typing of dengue viruses from clinical samples by using reverse transcriptase-polymerase chain reaction. J Clin Microbiol. 1992; 30:545-51.

15. Khawsak P, Phantana S, Chansiri K. Determination of dengue virus serotypes in Thailand using PCR based method. Southeast Asian J Trop Med Public Health. 2003; 34:781-5.

16. Lorono-Pino MA, Cropp CB, Farfán JA, Vorndam AV, Rodriguez-Angulo EM, Rosado-Paredes EP, et al. Common occurrence of concurrent infections by multiple dengue virus serotypes. Am J Trop Med Hyg. 1999; 61:725-30.

17. Dissanayake VH, Gunawardena ND, Gunasekara NC, Siriwardhana DR, Senarath N. Shift in the transmission pattern of dengue serotypes and concurrent infection with more than one dengue virus serotype. Ceylon Med J. 2011; 56:176-8.

18. Yingsiwaphat V, Siriyasatien P, Arunyingmongkol K, Krajiw S, Pupaibool J, Nisalak A, et al. Survival of dengue virus in the urine of acutely-infected patients - implications for pathogenesis and for a possible unrecognized mode of transmission for an arthropod-borne virus. The 17th European Congress of Clinical Microbiology and Infectious Diseases (ECCMID) and the 25th International Congress of Chemotherapy (ICC); March 31-April 4, 2007; Munich, Germany. London: Wiley-Blackwell; 2007. p. S15-6. [Abstract of oral presentation O64]

19. Bhatnagar J, Blau DM, Shieh WJ, Paddock CD, Drew C, Liu L, et al. Molecular detection and typing of dengue viruses from archived tissues of fatal cases by RT-PCR and sequencing: diagnostic and 
epidemiologic implications. Am J Trop Med Hyg. 2012; 86:335-40.

20. Boonpucknavig V, Bhamarapravati N, Boonpucknavig S, Futrakul P, Tanpaichitr P. Glomerular changes in dengue hemorrhagic fever. Arch Pathol Lab Med. 1976; 100:206-12.

21. Boonpucknavig V, Soontornniyomkij V. Pathology of renal diseases in the tropics. Semin Nephrol. 2003; 23:88-106.

22. Jessie K, Fong MY, Devi S, Lam SK, Wong KT. Localization of dengue virus in naturally infected human tissues, by immunohistochemistry and in situ hybridization. J Infect Dis. 2004; 189:1411-8.

23. Plongla R, Songchareon K, Arunyingmongkol K, Tantiwongse K, Kulwichit W. Presence of dengue virus genome in kidney tissue of adults without recent dengue infection: another piece of evidence of in vivo persistence of the virus. 22nd European Congress of Clinical Microbiology and Infectious Diseases (ECCMID); March 31-April 3, 2012; London, United Kingdom. London: Wiley-Blackwell; 2012. p. 188-9. [Abstract of poster P875] 